\title{
Application of ICT in Pests Control and Diseases Management of Food Crops
}

\author{
Okpara Okechukwu D. \\ National Weather Forecasting and Climate Research Centre (NWFCRC), \\ Nigerian Meteorological Agency (NIMET), Nnamdi Azikiwe International Airport, \\ Abuja-FCT, Nigeria.
}

\begin{abstract}
This paper proposes a web-based Agro-Information System (AIS) prototype that can support farmers with agricultural-related information about a given food crop. Consistency in the application of this information can help in improving crop yield, in controlling crop pests, in crop diseases treatment, and in enhancing the overall crop productivity. A prototype AIS capable of providing possible pest control, and suggesting disease treatment for the associated pathogens, has been developed and implemented using Open-source technologies.
\end{abstract}

\section{General Terms}

Information System.

\section{Keywords}

Agro-Information System (AIS), Crop diseases management, Crop productivity, ICT.

\section{INTRODUCTION}

Information is indispensable in the socio-economic and agricultural sectors of both developing and developed countries. Agro-Information System (AIS) can be used to provide information of major pests and diseases for crops and advice on crop protection. The public, government and agricultural decision-makers can obtain essential information and services provided by the AIS for use in areas such as agricultural disaster assessment, national vegetation monitoring, national crop yield forecasts and agro-advisories. To enhance agricultural productivity among rural farmers, it is often necessary to increase farmer's access to agricultural information and effective utilization of this information. The information provided must be in user-friendly form, easy to access, costeffective and well protected from unauthorized accesses [1].

\section{LITERATURE REVIEW}

It has been noted that highly developed software programming skills and technical expertise are critical for deploying ICTs [2].
A generic AIS architecture should have a number of design criteria such as security, multi-user, accessibility, and accuracy [3].

The delivery of agriculture-related services via ICT requires access to personal computers and the internet [4]. An AIS consists of components (subsystems), information related processes (generation, transformation, storage, retrieval, integration, diffusion and utilization), system mechanisms (interfaces and networks) and system operations (control and management) [5]. Information Systems deal with the deployment of information technology in organizations, institutions, and society at large [6]. A review of various models of information system processes such as development and transfer showed that information does not simply flow, but is continually being transformed and adapted through communication [7].

Agricultural knowledge and information system for farmers can justify the need for farmers to understand the technological principles of integrated pest management [8].

\section{THE WEB-BASED AGRO- INFORMATION SYSTEM DESIGN PROTOTYPE}

The AIS prototype is composed of four essential integrated system components. The components are:
a. user accounts management system;
b. user login and authentication system;
c. AIS database framework; and
d. SMS server platform.

The key components of the AIS prototype are shown in Figure 1. 


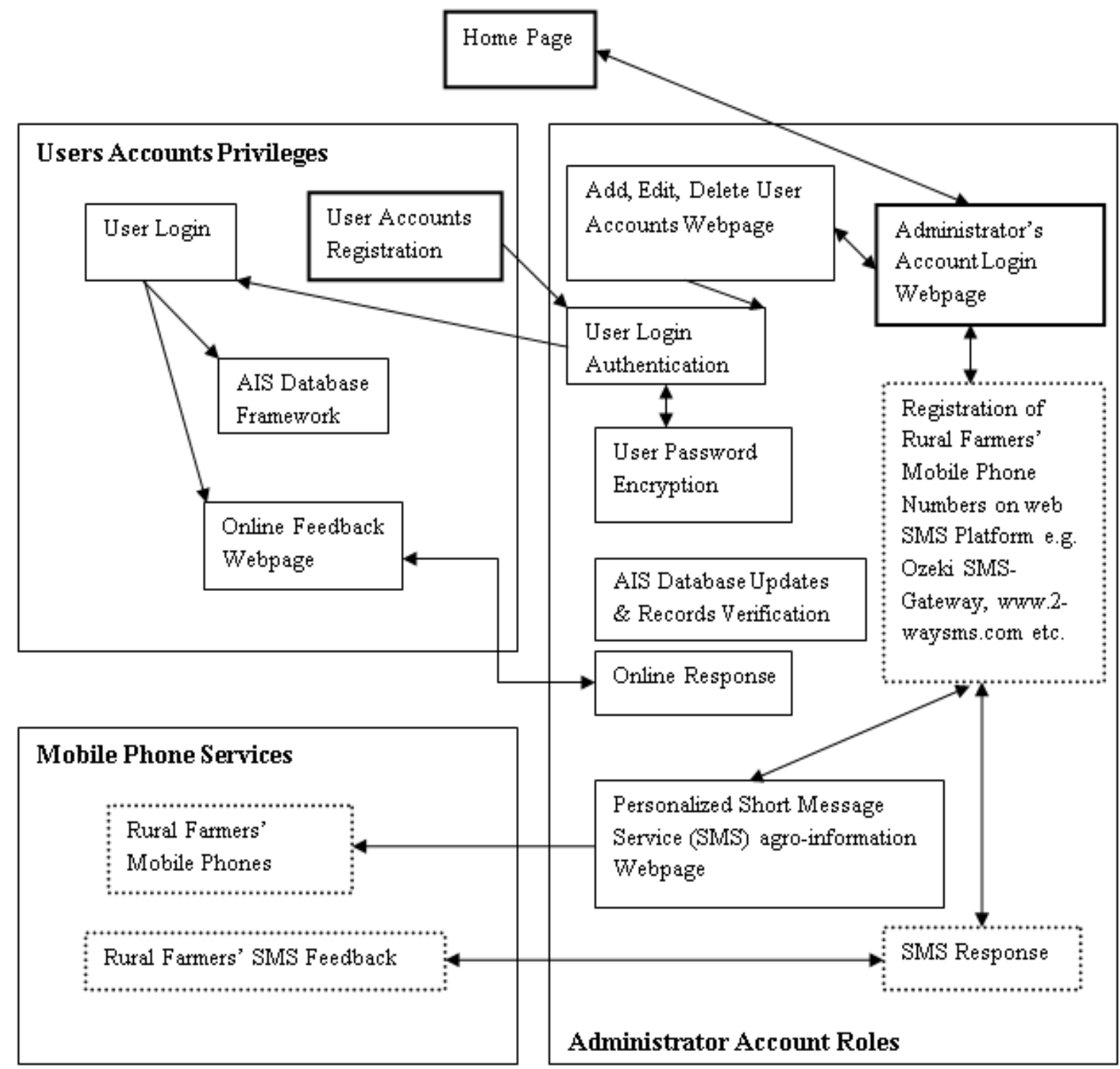

Figure 1: The conceptual layout of the Agro-Information System prototype

\section{DESIGN REQUIREMENTS}

The AIS meets the following design criteria and considerations:

1. Secured multi-user access: The users' accounts are protected using a password encryption technology. Simultaneous access through web and compatible mobile phone platforms is supported by the AIS.

2. Secured database: The AIS database can only be modified and updated through the administrator's account.

3. Software reusability, adaptability and licensing: The AIS is released under the Opensource GNU Public License (GPL), hence the software can be extended and improved by other programming experts around the world without any copyright infringements or proprietary software issues.

4. Availability and accessibility: The AIS was developed using an internet platform which comprises of a web programming package which consists of Apache web server, PHP, and MySQL database. Information can be sent to rural farmers by the administrator through the integrated Short Messaging Service (SMS) platform in the AIS website.

5. Integrity and verifiability: The information contained in the AIS can be corrected, checked, verified or updated by the Administrator if need be. 


\section{THE AIS DATABASE RAMEWORK}

The AIS database framework shows the data structure functionality of the system. There are four databases which contain different records in tables for any selected crop. Each selected crop has unique records that contain its own specific crop information. The AIS database framework is shown in Figure 2.

The Contents Database contain the following records in its table structure: Crop Name, Crop ID, Botanical Name, Variety, Time of Sowing, Planting Mid-season, Time of Harvesting, Soil Type, Fertilizer Type, Quantity of Fertilizer (kg/ha/yr), Rainfall Requirement (mm), Optimum Temperature Range $\left({ }^{0} \mathrm{C}\right)$, Sunshine Requirement.

The Pests Control Database contains the following records in its table structure: Pests, Control.

The Diseases Control Database contains the following records in its table structure: Diseases, Treatment.

The Pathogen Database contains the following records in its table structure: Pathogen, Associated Disease Caused.

A sample database template for specific food crop information is shown in Table 1.
Table 1. A Sample Food Crop Template

\begin{tabular}{|l|l|}
\hline Plant Name: & \\
Plant Group: & \\
Botanical Name: & \\
Time of Sowing: & \\
Mid-season: & \\
Time of Harvesting: & \\
Soil Type: & \\
Optimum Temperature: & \\
Fertilizer Type: & \\
Crop Usage: & \\
Importance: & \\
Major Pests: & \\
Nematodes - & \\
Insects - & \\
\hline & \\
Pests: & Control: \\
Diseases: & Diseases caused: \\
Pathogen: & \\
\hline
\end{tabular}

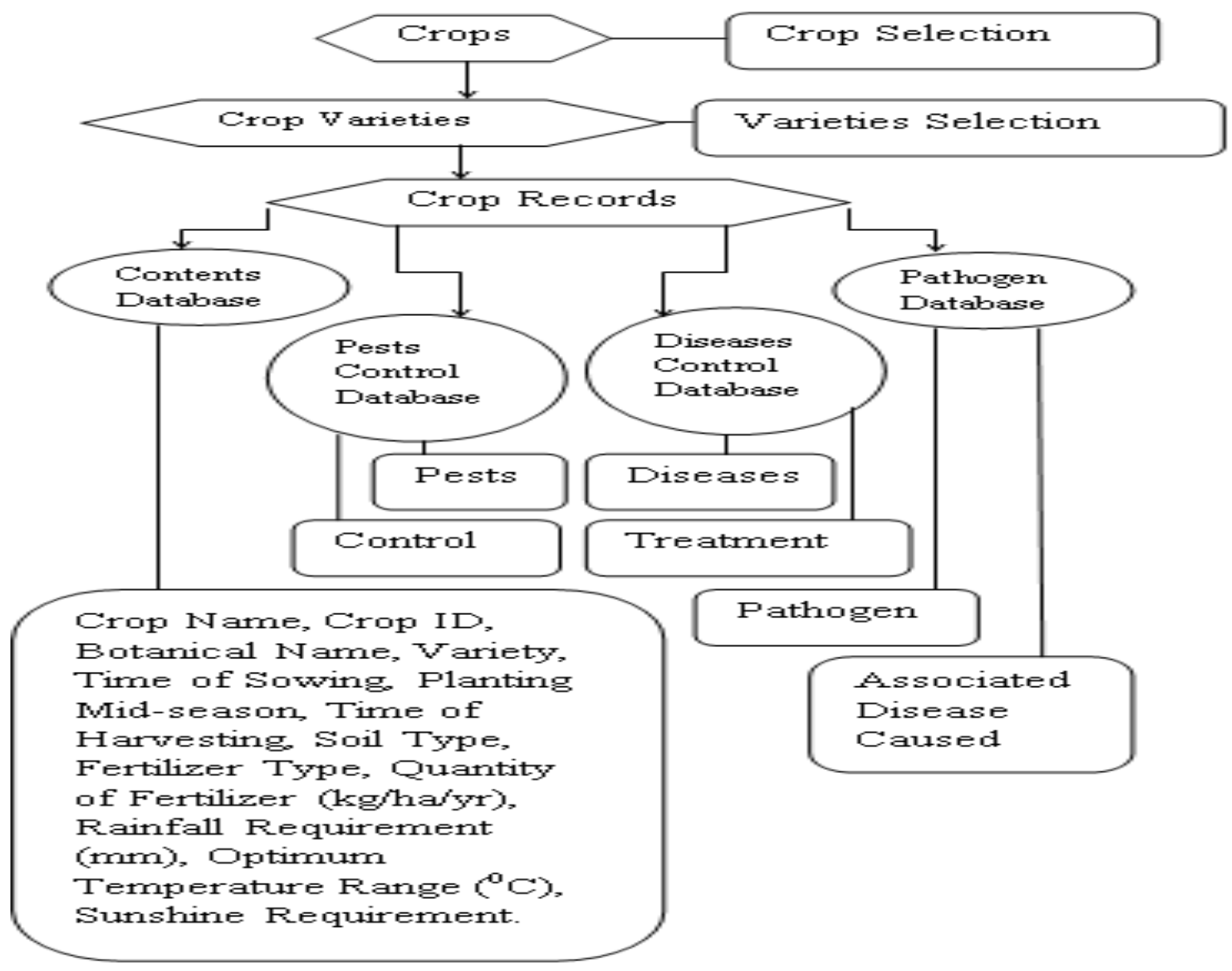

Figure 2: The Agro-Information System Database Framework 


\section{THE AGRO-INFORMATION SYSTEM PROTOTYPE IMPLEMENTATION}

The AIS prototype was developed on a microcomputer running Apache (version 2.4.7) web server. The dynamic data-driven webpages of the AIS were programmed using Improved MySQL (version 5.6.15) which is a widely used Open-source Relational Database Management System (RDMS), and PHP Hypertext Preprocessor (PHP) which is a server-side general purpose scripting language that is widely used for web development. MySQL was used for creating the Structured Query Language (SQL) databases. A combination of Hypertext Markup Language (HTML) tags, Cascading Style Sheets (CSS), and JavaScript clientside scripting language, were also used in creating the webpages of the AIS website. Notepad++ version 6.5.1 (2013) software was used as the text editor for writing the program codes for the AIS website.

The passwords of the Users' Accounts were encrypted using the 60-character hash string encryption system of the PHP 5.5's password_hash() function so as to protect the accounts from unauthorized accesses. For instance, the PHP password_hash() function encrypted the password of a farmer who registered with the password, "u2s2e $2 \mathrm{r}$ " as "\$2y\$10\$ZnkyPqQVqLmFv5YQ8ubrK.JOVQAczFoQwp TDR7vJg10D0JO/6NCea".

The Administrator's Account was equipped with a CreateRead-Update-Delete (CRUD) technology for the management of both the User Accounts and the AIS databases.

The SMS server platform was implemented using the Ozeki SMS-Gateway (www.ozeki.hu).

\section{TESTING OF THE AIS WEBSITE}

A sample run of the prototype AIS on a website that was locally hosted on a personal computer, using an Apache web server and viewed with a Flock version 2.6.1 web browser is shown in Figure 3. Figure 4 and Figure 5 shows a sample test run of Rice and Cassava food crops respectively. The information of both crops has been designed for the country, Nigeria, as an example.

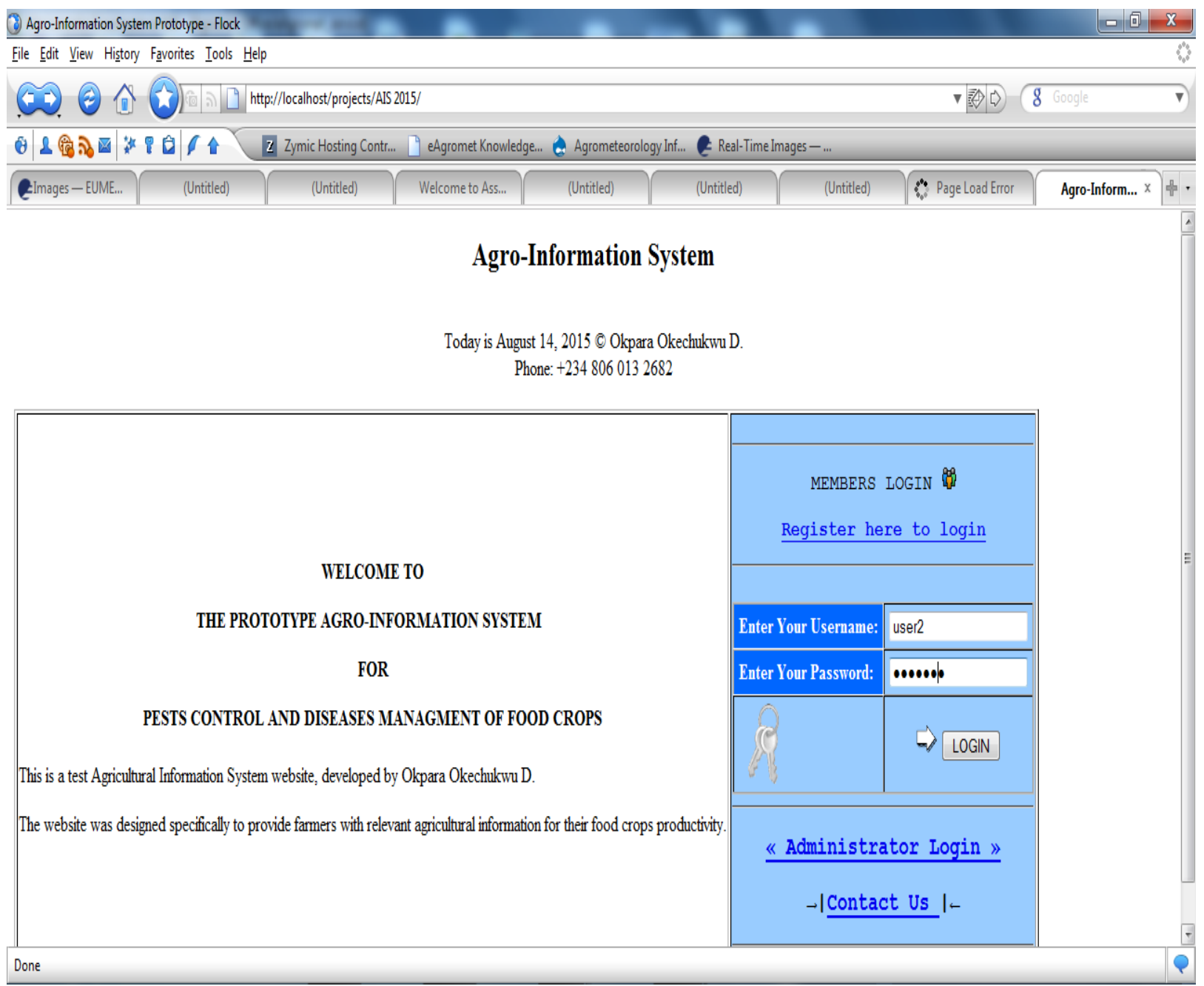

Figure 3: The Prototype Agro-Information System Website Home Page 
$\underline{\text { Go Back }}$

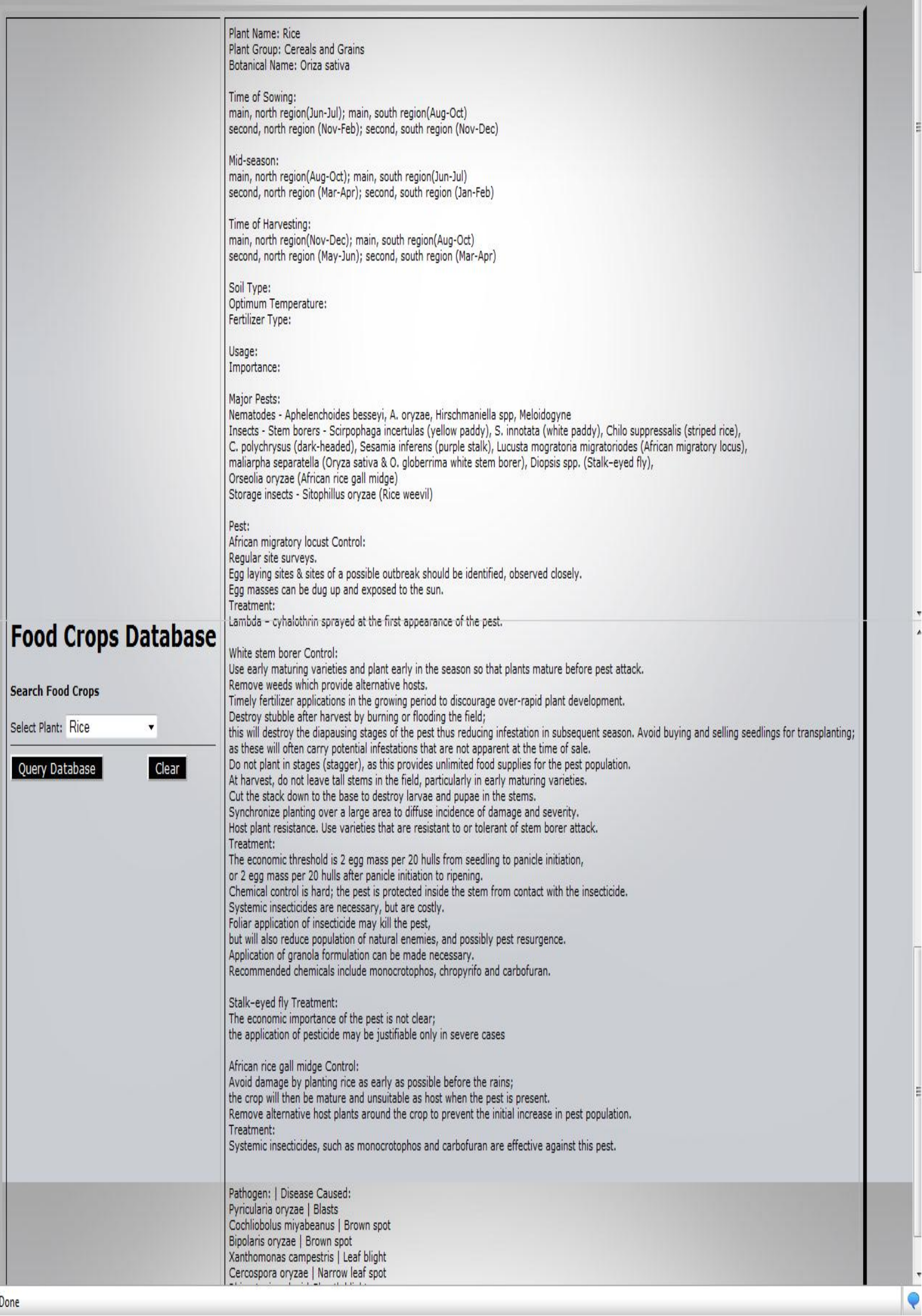

Figure 4: A Sample Crop Information of Rice as contained in the AIS database 


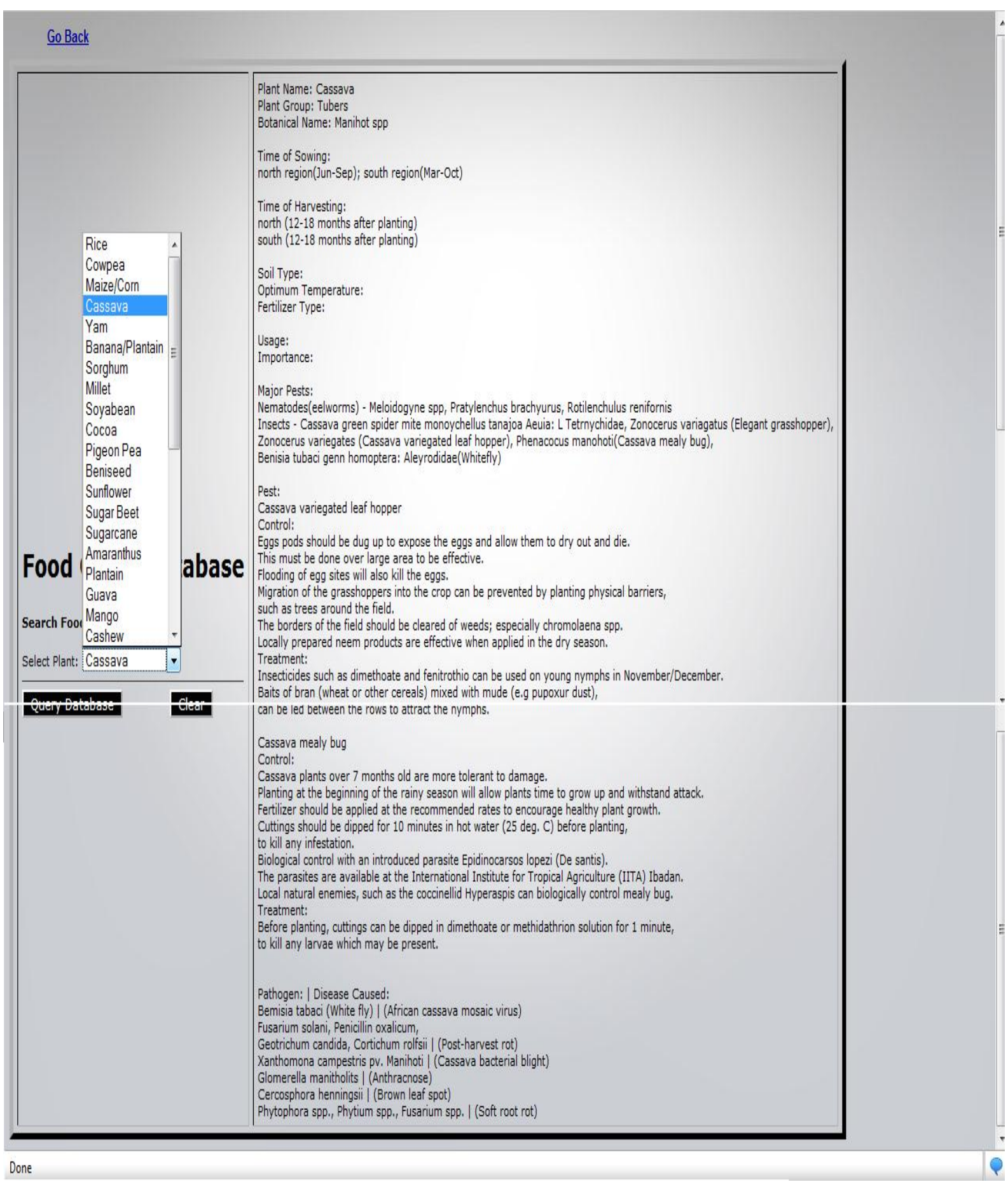

Figure 5: A Sample Crop Information of Cassava as contained in the AIS database

\section{CONCLUSION}

This study provided the basis for a prototype AIS development through which farmers can access crop pests control measures and crop diseases treatment information using Open-source web platform with SMS server integration. AIS can be used in generating and disseminating crop information. The web-based AIS software was released under the GNU Public License (GPL) which makes it complete Open-source software.
Agricultural consultants and government policy and decision-makers can use AIS services in ensuring adequate food supplies, food security, and sufficient farm income for the farmers. Farmers can also access or obtain both pest control and crop diseases information from the AIS; this can help them in protecting their food crops from crop pests and crop diseases effectively.

The information provided by the AIS was made available to rural farmers using SMS text messages. 
The information contained in the AIS can also be made accessible to rural farmers through other channels of communication such as radio, television, agricultural advisory bulletins and other suitable media.

The Agro-Information System proposed in this paper could be further developed by incorporating an embedded system, for instance, an agricultural expert system, which can analysis and automate the information-delivery processes between the information system databases on the website and the SMS server platform without any manual involvement by the administrator.

\section{REFERENCES}

[1] "ICT in Agriculture" retrieved from en.wikipedia.org/wiki/ICT_in_agriculture.htm accessed on July 20, 2015.

[2] "ICT Applications For Agricultural Risk Management" retrieved from www.ictinagriculture.org/sites/ictinagriculture.org/file s/final/Module11.pdf accessed on July 20, 2015.

[3] Ugwuishiwu, C.H., Udanor, C., and Ugwuishiwu, B.O. 2012. Application of ICT in Crop Production. International Journal of Soft Computing and Engineering. Volume-2, Issue-4, 227-231.
[4] "Mobile Applications in Agriculture" retrieved from http://www.syngentafoundation.org/_temp/Report_o n_mAgriculture_abridged_web_version.pdf accessed on July 20, 2015.

[5] "Agricultural Information Systems and Communication Networks: the case of dairy farmers in the Samsun province of Turkey" retrieved from www.informationr.net/ir/13-2/paper343.html accessed on July 21, 2015.

[6] Ciborra, C. 2002. Labyrinths of Information. Oxford: Oxford University Press. P.5.

[7] Garforth, C. and Usher, R. 1996. Methodologies for analyzing and improving the effectiveness of promotion and uptake pathways for renewable natural resources information and technology: a review paper. Working Paper 96/8. Reading: AERDD, The University of Reading.

[8] Ortiz, O. O. E. 1997. The information system for IPM in subsistence potato production in Peru: experience of introducing innovative information in Cajamarca Province. Unpublished doctoral dissertation, University of Reading, Reading, United Kingdom. 